\title{
Psychomotor Stimulant Addiction: A Neural Systems Perspective
}

\author{
Barry J. Everitt ${ }^{1}$ and Marina E. Wolf ${ }^{2}$ \\ ${ }^{1}$ Department of Experimental Psychology, University of Cambridge, Downing Street, Cambridge CB2 3EB, United \\ Kingdom, and 'Department of Neuroscience, Chicago Medical School, North Chicago, Illinois 60064-3095
}

The reinforcing (rewarding) effects of psychomotor stimulants (cocaine and amphetamine) depend on the mesocorticolimbic dopamine system innervating the nucleus accumbens (Wise, 1981; for review, see Koob, 1992), perhaps especially the shell subregion (Bassareo and Di Chiara, 1997). Prominent theories of addiction are based on adaptations associated with both sensitization to and withdrawal from repeated exposure to psychomotor stimulants (Robinson and Berridge, 1993; Koob and Le Moal, 2001). Great progress has been achieved toward revealing the nature of cellular and molecular adaptations in animal models of addiction (Hyman and Malenka, 2001; Koob and Le Moal, 2001; Nestler, 2001), many of which are similar, if not identical, to those implicated in models of learning and memory (Hyman and Malenka, 2001; Nestler, 2001).

One challenge in addiction research is to understand how molecular and cellular adaptations are related to altered functioning of neural systems that underlie compulsive drug-seeking behavior. This review highlights associative influences on psychomotor stimulant addiction, building on the view that plasticity in neural systems converging on the nucleus accumbens (Nac) and dorsal striatum (DS) is usurped by chronic drug selfadministration, leading to the aberrant engagement of pavlovian and instrumental learning processes. At a systems level, one product of the gradual strengthening or "consolidation" of behavior arising from the reinforcing action of drugs may be the eventual progression of addiction to a form of habit-based learning, in which voluntary control over drug use is lost and the propensity to relapse is high and readily precipitated by exposure to drug-associated stimuli (O'Brien and McLellan, 1996; Robbins and Everitt, 1999; Everitt et al., 2001; Hyman and Malenka, 2001).

In human cocaine addicts, otherwise neutral environmental stimuli, such as paraphernalia associated with drug-taking, become associated with the effects of cocaine through pavlovian conditioning (Childress et al., 1992). Subsequent exposure to these stimuli elicits powerful drug craving and precipitates relapse to drug-taking despite prolonged periods of abstinence (Childress et al., 1992; O'Brien and McLellan, 1996). Recent functional imaging studies have exploited the fact that craving

B.J.E. was supported by a Medical Research Council (MRC) program grant (G9537855) and an MRC Cooperative in Brain, Behaviour and Neuropsychiatry. M.E.W. was supported by United States Public Health Service Grants DA09621, DA13006, and Independent Scientist Award DA00453 and a National Alliance for Research on Schizophrenia and Depression Independent Investigator Award. We thank Francis White for his encouragement and editorial expertise.

Correspondence should be addressed to Barry J. Everitt, Department of Experimental Psychology, University of Cambridge, Downing Street, Cambridge CB2 3EB, UK, E-mail: bje10@cus.cam.ac.uk, or Marina E. Wolf, Department of Neuroscience, Chicago Medical School, 3333 Green Bay Road, North Chicago, IL 60064-3095, E-mail: marina.wolf@finchcms.edu.

Copyright (ㄷ) 2002 Society for Neuroscience $0270-6474 / 02 / 223312-09 \$ 15.00 / 0$ can be evoked in human subjects exposed to images and other stimuli, including biographical scripts, associated with cocaine taking. Consistently, the amygdala, anterior cingulate cortex $(\mathrm{ACg})$, and orbital prefrontal cortex (PFC) are activated in these studies, along with (less consistently) the striatum and dorsolateral PFC (Grant et al., 1996; Maas et al., 1998; Childress et al., 1999; Wang et al., 1999). These structures have been implicated not only in conditioning processes, but in executive functions such as inhibitory control (for review, see Robbins and Everitt, 1999; Everitt et al., 2001), both of which play important roles in the development of cocaine addiction.

Understanding the impact of pavlovian conditioning on drug-seeking behavior has been achieved by combining behavioral studies with in vivo neurochemical monitoring, cellular imaging approaches, and intracranial injection of drugs. These complementary approaches have revealed neuronal populations and neurotransmitters engaged during pavlovian conditioning and retrieval in a cocaine-seeking setting and the impact of cocaine-associated stimuli on drug seeking and its reinstatement after abstinence.

\section{Corticostriatopallidal systems (Fig. 1) and associative mechanisms underlying cocaine addiction}

Cue-controlled cocaine seeking

Stimuli associated with drug taking both elicit drug seeking and reinforce instrumental acts directed toward procuring the drug (Robbins and Everitt, 1999; Everitt et al., 2001). One model of cocaine seeking, sensitive to the contingency between instrumental behavior and drug administration as well as the presence of drug-associated stimuli, is provided by a second-order schedule of reinforcement. In this procedure, rats respond for prolonged periods of time to obtain an inf usion of cocaine; this drug seeking depends critically on the contingent presentation of cocaineassociated cues that act as conditioned reinforcers (Arroyo et al., 1998; Everitt and Robbins, 2000). Rats with lesions of the basolateral amygdala (BLA) were unable to acquire such cuecontrolled cocaine seeking (Whitelaw et al., 1996), consistent with an earlier literature implicating the BLA in conditioned reinforcement (Everitt et al., 1999). Reversible inactivation of the caudal, but not rostral, BLA also disrupted the maintenance of cocaine seeking under a second-order schedule (Kantak et al., 2002), indicating that the BLA plays an important role that endures beyond initial acquisition. Furthermore, rats with lesions of the ACg or medial PFC (mPFC) showed persistent responding for cocaine, but responding was no longer under the control of contingent presentations of cocaine-associated cues (Weissenborn et al., 1997), indicating that these cortical structures, along with the BLA, contribute to associative mechanisms controlling cocaine seeking, as also suggested by functional imaging studies (Grant et al., 1996; Childress et al., 1999). Inactivation of the NAc 


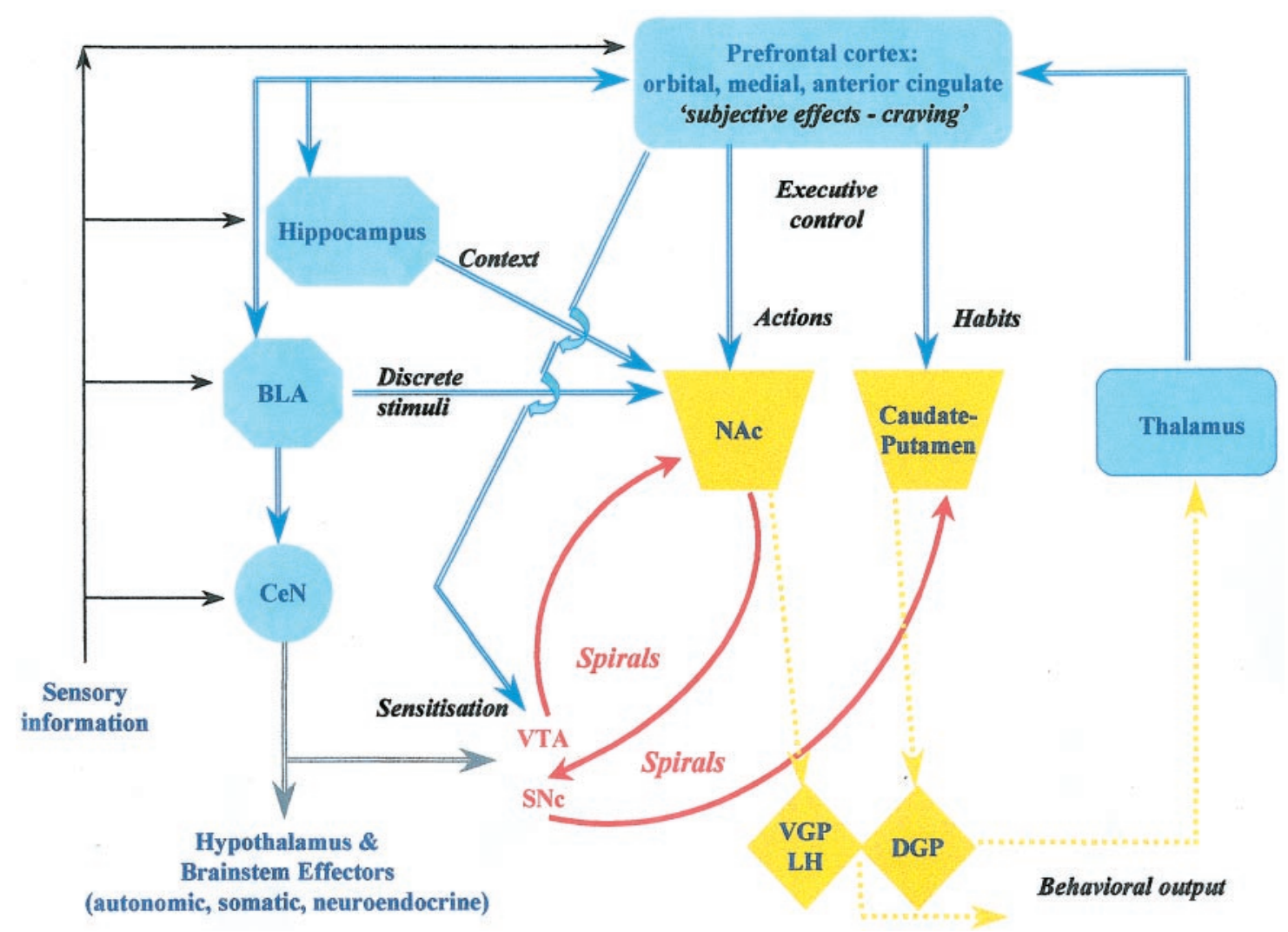

Figure 1. A highly schematic representation of limbic cortical-ventral striatopallidal circuitry that tentatively localizes particular functions discussed in the text: (1) sensitization - ventral tegmental area and also the nucleus accumbens, via glutamate-dopamine interactions; (2) processing of discrete and contextual drug-associated conditioned stimuli-basolateral amygdala and hippocampal formation, respectively; (3) goal-directed actions ("actionoutcome" associations)—nucleus accumbens; (4) "habits" (stimulus-response learning)—-dorsal striatum. Both 3 and 4 involve interactions between cortical afferents and striatal processes modulated by dopamine. (5) "Executive control"- prefrontal cortical areas; (6) subjective processes, such as craving, activate areas such as orbital and anterior cingulate cortex, as well as temporal lobe structures including the amygdala, in functional imaging studies; (7) "behavioral output" is intended to subsume ventral and dorsal striatopallidal outflow via both brainstem structures and reentrant thalamocortical loop circuitry; (8) "spirals" refers to the serial, spiraling interactions between the striatum and midbrain dopamine neurons that are organized in a ventral-to-dorsal progression (Haber et al., 2000); (8) blue arrows indicate glutamatergic pathways; orange arrows indicate GABAergic pathways; red arrows indicate dopaminergic pathways. The transmitter used by central amygdala neurons is less certain but is probably glutamate and also a neuropeptide(s). BLA, Basolateral amygdala; $C e N$, central nucleus of the amygdala; $V T A$, ventral tegmental area; $S N c$, substantia nigra pars compacta. This diagram is modified from Altman et al. (1996).

core also impaired acquisition of cocaine seeking under a secondorder schedule (Ito et al., 2001), further suggesting that limbic cortical structures, via their glutamatergic projections to the NAc, subserve conditioned influences on cocaine seeking. Supporting this view, infusions of an AMPA, but not an NMDA, receptor antagonist into the NAc core, but not shell, greatly attenuated cue-controlled cocaine seeking (Di Ciano and Everitt, 2001). Additionally, systemic treatment with dopamine (DA) D3 receptor ligands also greatly reduced cue-controlled cocaine seeking (Pilla et al., 1999; Di Ciano et al., 2001). Although the precise site of action of these DA D3 ligands is unclear, the restricted regional expression of D3 receptors strongly implicates targets within limbic corticostriatal circuitry: DA D2/D3 receptors within the amygdala have already been implicated in pavlovian conditioning (Hitchcott and Phillips, 1998).

Many of the same pathways, in particular glutamatergic projections to the NAc, are implicated by studies using other models to study cocaine-conditioned responses, consistent with the fact that the NAc receives convergent inputs from many cortical regions activated by cocaine-related cues. For example, intra-NAc administration of an AMPA receptor antagonist blocked psychostimulant-induced conditioned place preference
(Layer et al., 1993; Kaddis et al., 1995). Intra-NAc AMPA infusion produced heightened motor responses in rats that had previously received cocaine in the test environment (Bell and Kalivas, 1996), whereas a cocaine challenge in the training environment increased NAc glutamate levels in rats for which the environment had previously been paired with cocaine (Bell et al., 2000). Moreover, during a drug-free microdialysis test session, discrete cocaineassociated stimuli increased NAc glutamate levels, and this effect could be temporally dissociated from the locomotor response itself (Hotsenpiller et al., 2001). A striking finding was that basal extracellular glutamate levels in the NAc, measured before introduction of the cocaine cue, were markedly reduced in the paired group (Hotsenpiller et al., 2001). Because both groups had the same cocaine history, this neurochemical change must be attributed to the fact that one group had formed an association between cocaine and the discrete cue during the weeks before the microdialysis experiment. Paired subjects tested in the cocaine-paired environment also showed decreased basal glutamate levels in the NAc compared with saline controls (Bell et al., 2000). These findings demonstrate that conditioning processes have marked effects on glutamate transmission, consistent with the central role of glutamate in plasticity and learning, and suggest that addictive behavior 
may involve glutamate-dependent neuroplasticity in limbic corticostriatal systems.

Immediate-early gene expression has also been used to map neuronal circuits underlying drug-conditioned behaviors. Pairing an environment or discrete stimulus with experimenteradministered cocaine or amphetamine results in a conditioned locomotor response to the stimulus alone that is accompanied by increased expression of c-fos in limbic cortical regions that varied somewhat among studies but included the PFC, ACg, BLA, and NAc (Brown et al., 1992; Mead et al., 1999; Franklin and Druhan, 2000a; Hotsenpiller et al., 2002). Moreover, this conditioned locomotion was disrupted by infusion of GABA agonists into the PFC or the NAc, but not into the BLA (Franklin and Druhan, 2000b). Psychomotor stimulants also induced quantitatively and qualitatively different patterns of Fos expression when administered in a novel environment, a finding relevant to the ability of novelty to enhance locomotor sensitization and emphasizing the importance of environmental stimuli in determining some stimulant drug effects (Badiani et al., 1998, 1999; Day et al., 2001; Uslaner et al., 2001). Exposure to a discrete stimulus associated with self-administered cocaine also increased expression of the plasticity-associated gene $\gamma$ protein kinase $\mathrm{C}$ in the amygdala, medial PFC, ACg cortex, and NAc, although the regional pattern of expression depended on whether the stimulus was presented unexpectedly or contingent on instrumental responses (Thomas and Everitt, 2001), an issue that we return to below.

Reinstatement of cocaine seeking by cocaine-associated stimuli After extinction of drug self-administration, exposure to drugassociated stimuli, experimenter-administered drug, or stress reinstates drug-seeking behavior, i.e., responding in extinction on a lever that previously resulted in drug infusions. This procedure was introduced, refined, and detailed by Stewart and colleagues (de Wit and Stewart, 1981; Shaham et al., 1994) and has led to many investigations of psychological and neurobiological mechanisms of relapse. We focus here on cue-induced reinstatement of cocaine seeking, because this not only models key aspects of relapse in human addicts, but also reveals the involvement of limbic cortical-ventral striatopallidal systems (Fig. 1) in cocaine addiction. A basic feature of this procedure is that established drug taking is first extinguished and then its reinstatement is subsequently studied. Although an effective and fruitful model of relapse, extinction of drug self-administration is not a means by which human addicts achieve abstinence, which is more likely to arise through an active decision to abstain or through forced abstinence. Moreover, because the extinguished response is so readily reinstated, it is unlikely that extinction training will provide an effective clinical approach to treatment. On the other hand, non-reinforced exposure to cocaine-associated stimuli, and thereby extinction of their motivational effects, might be a useful therapeutic strategy (O'Brien et al., 1990, 1992; Robbins et al., 1992), although cue exposure in the clinic is unlikely to be sufficient because the cues may remain potent elicitors of craving in the original drug-associated environment.

The BLA is critical for reinstatement of cocaine seeking after extinction after exposure to cocaine cues. Bilateral excitotoxic lesions of the BLA (Meil and See, 1997) or its inactivation by infusion of tetrodotoxin (TTX) (Grimm and See, 2000) or lidocaine (Kantak et al., 2002) all prevent reinstatement of cocaine seeking after extinction, the latter study using a second-order schedule procedure. In addition, although the BLA is important in both the acquisition and expression of conditioned relapse to cocaine seeking, inactivation of the central amygdala $(\mathrm{CeN})$ prevented only the expression of conditioned relapse (Kruzich and See, 2001), suggesting the existence of dissociable processes within the amygdala [see below and Everitt et al. (2000)]. Although antagonism of NMDA or AMPA receptors in the BLA failed to prevent cued reinstatement of cocaine seeking, infusion of a D1, but not a D2, DA receptor antagonist did (See et al., 2001). These results suggest a role for DA in the amygdala in conditioned influences on cocaine seeking, but they also need to be reconciled with earlier findings suggesting involvement of amygdala D2/D3 receptors in conditioning (Hitchcott and Phillips, 1998).

Given that exposure to cocaine cues increases both DA (Di Ciano et al., 1998; Ito et al., 2000) and glutamate (Hotsenpiller et al., 2001) release in the NAc, it is perhaps surprising that inactivation of the NAc by TTX did not affect conditioned reinstatement of cocaine seeking but instead prevented reinstatement induced by a priming injection of cocaine (Grimm and See, 2000). Indeed, the importance of the NAc in drug-primed reinstatement has been confirmed and shown to depend on glutamate transmission there (Cornish et al., 1999; Cornish and Kalivas, 2000). However, systemic psychopharmacological studies have shown that D2, but not D1, DA receptor agonists can precipitate reinstatement of cocaine seeking (Self et al., 1996) and that both D1 and D2/D3 DA receptor antagonists can prevent conditioned reinstatement (Weiss et al., 2001). Determining the central sites of action of these DAergic effects on reinstatement of cocaine seeking remains an important goal. These effects might depend principally on DA receptors in the NAc, which mediate not only the reinforcing effects of cocaine (Koob, 1992) but also the potentiation of conditioned reinforcement (Taylor and Robbins, 1986; Wolterink et al., 1993). However, the amygdala is clearly an important locus of DA effects on pavlovian conditioning and conditioned reinstatement, indicating that DAergic processes in limbic cortical sites, rather than at the striatal termination of the projections from these cortical areas, may contribute significantly to conditioned influences on cocaine seeking. In a study of cocaine-primed (rather than conditioned) reinstatement, the importance of a medial PFC-ventral striatopallidal system (Fig. 1) was established, and the medial PFC, not the striatum, was identified as the primary site at which DA receptor blockade prevented the relapse-inducing effects of cocaine (McFarland and Kalivas, 2001).

Distinct pathways are apparently involved, therefore, in reinstatement produced by conditioned cues and cocaine priming injections; notably, the BLA is implicated only in the former (Grimm and See, 2000). Using microinjections of GABA agonists to selectively inactivate brain regions or combinations of regions, McFarland and Kalivas (2001) showed that cocaine-induced reinstatement depended on sequential information flow between the ventral tegmental area (VTA), dorsal PFC, NAc core, and ventral pallidum and suggested that cue-induced reinstatement depends on similar circuitry, but through a different point of entry involving the BLA (McFarland and Kalivas, 2001) (Fig. 1). Studies in which Fos expression was used to map neuronal circuits involved in drug-seeking behavior triggered by cocaine-paired environmental stimuli versus cocaine priming injections further support the idea that overlapping, but distinct, structures are involved in these responses, although the $\mathrm{ACg}$ cortex may be common to both (Neisewander et al., 2000).

The vigor or degree of conditioned reinstatement of cocaine seeking increases with increasing duration of withdrawal from 
cocaine (Grimm et al., 2001), suggesting that neuroadaptations to chronic cocaine self-administration and withdrawal interact with the motivation to seek cocaine, especially, but not exclusively, when cocaine cues are present. These findings may provide insight into the possible mechanisms that underlie the persistence or "incubation" of cocaine seeking in abstinent cocaine addicts when exposed to similar stimuli.

Although limbic cortical-ventral striatopallidal systems are implicated in the conditioned control of drug seeking and reinstatement after extinction, much remains to be established in terms of the processes occurring in cortical and subcortical structures and the ways in which different subsystems interact, for example, those involving the amygdala, the hippocampal formation, and the medial or orbital PFC. Although the BLA mediates reinstatement after exposure to discrete, cocaine-associated stimuli, the hippocampus may underlie the motivational impact of contextual stimuli. Interestingly, theta burst stimulation of the hippocampus has been shown to reinstate extinguished cocaine seeking in a manner that depended on glutamate transmission in the VTA, and this was suggested to mimic the process by which reinstatement occurs when animals are placed in a context associated with drug taking rather than in response to discrete cocaine cues (Vorel et al., 2001). This view accords with data suggesting differential involvement of the amygdala in conditioning to discrete stimuli and the hippocampal formation in conditioning to contextual (or spatial) stimuli (Selden et al., 1991; McDonald and White, 1993). Moreover, electrophysiological and in vivo neurochemical studies have demonstrated that hippocampal, amygdala, and PFC projections interact in the NAc in a way that is modulated by mesolimbic DA and that, in turn, can modulate the release of DA (O'Donnell and Grace, 1995; Di Ciano et al., 1998; Floresco et al., 2001). Thus, hippocampal, amygdala, and PFC mechanisms may influence cocaine seeking through their convergent projections to the NAc, perhaps competing for access to response strategies subserved by different cortical-striatopallidothalamocortical reentrant loops (Fig. 1).

One feature of conditioned drug seeking and reinstatement is that pavlovian associations between discrete stimuli or contexts and the effects of cocaine can be established in different ways, and equally important, the particular manner of presentation of these stimuli subsequently determines the behavioral response. Different kinds of associations are formed during pavlovian conditioning, and pavlovian conditioned stimuli can elicit or support instrumental behavior, such as drug-seeking, in ways that depend on the engagement of dissociable neural systems (for review, see Everitt et al., 1999; Holland and Gallagher, 1999; Parkinson et al., 2000a). Discrete stimuli (light, tone) can be paired with each dose of self-administered cocaine (Meil and See, 1996; Arroyo et al., 1998; Self and Nestler, 1998), with noncontingent cocaine injections (Kruzich et al., 2001), or can serve as a discriminative stimulus $\left(\mathrm{DS}^{+}\right)$that signals the availability of cocaine (Weiss et al., 2001). The effects of subsequent presentation of these stimuli vary considerably. Thus, contingent presentations of a cocaineassociated stimulus (acting as a conditioned reinforcer) support cocaine seeking and reinstatement (Meil and See, 1997; Arroyo et al., 1998; Kruzich et al., 2001), whereas noncontingent presentations of the same stimulus, or of a classically conditioned stimulus, do not precipitate reinstatement (Kruzich et al., 2001). However, noncontingent presentation of a cocaine DS + that previously signaled cocaine availability (rather than a cocaine infusion) caused long-lasting reinstatement of cocaine seeking (Weiss et al., 2001) that was associated with both increased DA release in amygdala and NAc (Weiss et al., 2000) and c-fos expression in BLA and $\mathrm{ACg}$ that was itself blocked by a DA D1 receptor antagonist (Ciccocioppo et al., 2001).

Parallel studies of pavlovian conditioning have shed light on these intriguing differences. Conditioned reinforcement depends critically on the BLA (Cador et al., 1989; Burns et al., 1993) and its interactions with the NAc (Everitt et al., 2000). This accords well with the effects of amygdala manipulations on cue-controlled cocaine seeking and reinstatement. But discriminated approach to appetitive pavlovian stimuli depends on the $\mathrm{CeN}$ of the amygdala, not the BLA, and also on an ACg-NAc system and its DA innervation (Parkinson et al., 2000a,b). Furthermore, the ability of noncontingent presentations of pavlovian stimuli to potentiate instrumental behavior (pavlovian-instrumental transfer) also depends on the CeN and NAc, but not the BLA (Corbit et al., 2001; Hall et al., 2001). This potentiation of instrumental behavior by pavlovian stimuli is amplified by increased DA in the NAc shell in a way that is itself subject to sensitization (Wyvell and Berridge, 2000, 2001), perhaps representing the sensitized conditioned incentive salience that underlies drug "wanting," the process at the heart of the incentive salience theory of addiction (Robinson and Berridge, 1993). However, the process of pavlovian-instrumental transfer has not been studied directly in the context of drug seeking and its reinstatement, although the dramatic and persistent elevation of cocaine seeking in the presence of a DS+ previously paired with cocaine (Weiss et al., 2001) might reflect the impact of this process on relapse, a key element of addiction. This convergence of experiments investigating the neural basis of pavlovian conditioning underpinned by learning theory, together with those investigating associative mechanisms in addiction, offers promise for understanding the complexities of cocaine seeking and its relapse (Everitt et al., 2000).

\section{Addiction: the transition to compulsive drug seeking}

From the above review, it might be suggested that psychostimulant (and other drug) addiction can be understood in terms of the aberrant engagement of pavlovian and instrumental learning processes. Goal-directed actions by which animals and humans seek and take drugs may become firmly established high in the response repertoire through the impact of self-administered drugs on instrumental learning. In addition, stimuli consistently present in the environment gain motivational power through their predictive association with drugs and thereby elicit and support drug seeking and precipitate relapse.

This view is consistent with the role of midbrain DA neurons in functions more complicated than simple "reward." Midbrain DA neurons respond to unpredicted rewards, and with training this response transfers to stimuli predictive of rewards (Schultz et al., 1997; Schultz and Dickinson, 2000). By signaling reward prediction errors, DA may act as a teaching signal for striatal learning (Schultz and Dickinson, 2000). DA-dependent processes are involved in the development of stimulus-response (S-R) habits (Robbins et al., 1990; Packard and McGaugh, 1996) and the consolidation of habit learning (Packard and White, 1989, 1991). Midbrain DA neurons innervate the striatal, cortical, and limbic regions implicated in addiction, so drug effects on DA neuronal activity may be important for synaptic "learning" throughout limbic-cortical circuitry.

\section{Clues about circuitry from studies of behavioral sensitization}

Another important source of information about systems involved in addiction arises from studies of behavioral sensitization, which 
refers to the progressive enhancement of species-specific behavioral responses to drugs of abuse that develops over the course of repeated drug exposure and persists after long periods of withdrawal. As mentioned above, sensitization occurs not only to the locomotor activating effects of psychostimulants but perhaps also to the incentive motivational effects of drugs of abuse, i.e., wanting (Robinson and Berridge, 1993; Deroche et al., 1999). Previous exposure to cocaine or amphetamine, resulting in locomotor sensitization, promotes drug self-administration (Horger et al., 1990; Mendrek et al., 1998; Lorrain et al., 2000) and enhances stimulus-reward learning and responding for conditioned reward (Taylor and Horger, 1999; Taylor and Jentsch, 2001). The expression of sensitization is also associated with the reinstatement of self-administration after long-term extinction (De Vries et al., 1998), whereas environmental stimuli and conditioning strongly modulate sensitization in rats, as well as drug craving in humans (Robinson et al., 1998).

The development of sensitization requires a transient increase in the activity of glutamate transmission between PFC and VTA DA neurons (Fig. 1), leading to an activation of DA cell firing that somehow transfers sensitization to forebrain sites (NAc) that are important for its maintenance and expression. Sensitization is initiated by stimulant actions in the VTA, and its development is blocked by intra-VTA administration of glutamate receptor antagonists or by ibotenic acid lesions of the PFC. A transient increase in excitatory drive to VTA DA neurons occurs shortly after discontinuing stimulant administration (for review, see Wolf, 1998), suggesting that plasticity at synapses between glutamatergic afferents and VTA DA neurons is responsible for driving downstream changes related to sensitization, an idea directly supported by evidence that cocaine sensitization is accompanied by long-term potentiation (LTP) in VTA DA neurons (Ungless et al., 2001). Although it was originally imagined that such plasticity occurred between glutamate terminals originating in PFC and midbrain DA neurons, anatomical studies have shown that PFC afferents to the VTA synapse on mesoaccumbens GABA, rather than DA, neurons (Carr and Sesack, 2000). So the route of communication between PFC and VTA may be indirect, perhaps involving PFC projections to the laterodorsal tegmentum and neighboring mesopontine nuclei, which in turn send excitatory glutamatergic and cholinergic projections to the VTA (Forster and Blaha, 2000). The VTA also receives excitatory drive from the bed nucleus of the stria terminalis (George and Aston-Jones, 2001). Adding to the potential complexity of circuitries involved in induction mechanisms, the BLA also participates in the development of behavioral sensitization (Kalivas and Alesdatter, 1993; Wolf et al., 1995), and the NAc, traditionally associated with expression mechanisms, may also participate under some conditions (Khan and Shoaib, 1996). Thus, several components of limbic-corticostriatal circuits may contribute to sensitization, perhaps explaining the ability of very different previous experiences to lead to a similar outcome, i.e., enhanced responsiveness to psychostimulants.

The circuitry involved in expression of sensitization is less well established. Some studies indicate that it requires activation of glutamatergic projections from dorsal PFC to the NAc core (Pierce et al., 1998), whereas others indicate that PFC lesions that prevent development of sensitization do not alter its expression (Li et al., 1999). Yet there is an emerging consensus that the maintenance of sensitization may be associated with loss of inhibitory DA tone in the PFC, leading to a loss of inhibitory control over PFC projections to the NAc and other targets (Karler et al., 1998; Prasad et al., 1999). How might this contribute to sensitization of incentive-motivational processes related to drug seeking? Acutely increased DA release in the PFC may send PFC neurons into a depolarized "up-state" and thus increase corticofugal excitatory transmission (Lewis and O'Donnell, 2000). Stimulation of the PFC usually suppresses the activity of BLA projection neurons via inhibitory interneurons that suppress sensory cortical inputs to BLA, whereas BLA DA release may augment activation of BLA by sensory cortical inputs and dampen PFC regulation of BLA outflow (Rosenkranz and Grace, 2001). If, in the sensitized state, there is loss of inhibitory tone in the PFC, this would impair PFC-induced inhibitory regulation of BLA neurons, and the enhancing effects of DA release on BLA outflow would be unopposed. The resulting enhancement of excitatory drive from BLA to NAc could contribute to many glutamate-dependent mechanisms implicated in drug and conditioning effects in the NAc (Rosenkranz and Grace, 2001). This is consistent with theories of addiction that combine augmented conditioned reward with loss of inhibitory control mechanisms and the development of impulsivity (Jentsch and Taylor, 1999; Robbins and Everitt 1999).

\section{Transitional mechanisms related to corticostriatal plasticity}

As reviewed elsewhere, the striatum might be a critical site at which cellular and molecular adaptations to chronically administered drugs affect learning (Hyman and Malenka, 2001; Nestler, 2001). Behaviorally, the NAc core and its DA innervation are involved in the acquisition of pavlovian approach (Kelley et al., 1997; Parkinson et al., 2000b) and instrumental learning (SmithRoe and Kelley, 2000), whereas the DS is implicated in habit learning (Mishkin et al., 1984). Both DA and glutamate receptors are implicated in learning processes in striatal and limbic cortical structures (Baldwin et al., 2000; Berke and Hyman, 2000). Although NAc DA may be especially responsive to many drugs of abuse initially (Di Chiara and Imperato, 1988), the fact that DA transmission is increased in both the NAc and DS when drugs are self-administered over extended periods of time may contribute powerfully to aberrant learning involving both structures. Moreover, adaptations to chronic drug exposure are often seen in both NAc and DS (Letchworth et al., 2001; Nestler, 2001).

Compulsive drug use is characterized by behavior that is inflexible, because it persists despite considerable cost to the addict, may become dissociated from subjective measures of drug value (Robinson and Berridge, 1993), and is elicited by specific environmental stimuli (Childress et al., 1992), and yet, at least initially, it involves complex, goal-directed behaviors for procuring and taking a drug. One hypothesis is that limbic cortical-ventral striatopallidal circuits that underlie goal-directed drug seeking eventually consolidate habitual, S-R drug seeking through engagement of corticostriatal loops operating through the dorsal striatum (Robbins and Everitt, 1999; Everitt et al., 2001). This hypothesized progression from action to habit, the putative "switch" from drug abuse to addiction (Leshner, 1997), may have its neural basis within the recently described "spiraling" loop circuitry of the striatum (Fig. 1), by which each striatal domain regulates its own DA innervation and that of its adjacent domain in a ventral-to-dorsal, NAc-to-DS progression (Haber et al., 2000). Chronically self-administered drugs, through their ability to increase striatal DA, may consolidate this ventral-to-dorsal striatal progression of control over drug seeking as a habitual form of responding. There is little direct evidence of this from studies of addiction in animals, but a progressive spread from 
NAc to DS in DA transporter binding has been reported in the transition from acute to chronic cocaine self-administration in monkeys (Letchworth et al., 2001). Moreover, in well established cocaine seeking under a second-order schedule, elevated DA release is seen in the DS and not the NAc, although DA release in the NAc remains responsive to pavlovian presentations of cocaine-associated stimuli at this time (R. Ito, J. W. Dalley, T. W. Robbins, and B. J. Everitt, unpublished observations).

The transition from voluntary drug seeking to a compulsive habit may also depend on the disruption of executive control provided by descending influences on striatal mechanisms from the PFC (Shallice, 1996; Robbins and Everitt, 1999). Jentsch and Taylor (1999) have also proposed that impulsivity, resulting from frontostriatal dysfunction, plays an important role in addiction that acts synergistically with sensitization of S-R mechanisms to produce compulsive drug-seeking behavior. Recent evidence indicates that repeated drug exposure alters cortical cognitive function and leads to loss of inhibitory control mechanisms, including previously conditioned responses (Jentsch et al., 2002). Such changes may reflect disruption of orbital PFC efferents to the striatum as a result of chronic drug exposure; e.g., there are major decreases in the functional activation of the orbital PFC in human cocaine and methamphetamine addicts (Volkow and Fowler, 2000; Goldstein et al., 2001). This "tuning out" of the PFC might promote habitual drug-seeking/taking behavior (Volkow and Fowler, 2000) as well as impair cognitive decision making, as has been reported in long-term amphetamine abusers (Rogers et al., 1999). There have been no direct tests of this hypothesis, but excitotoxic lesions of the mPFC facilitate the acquisition of drugseeking but not food-seeking behavior (Weissenborn et al., 1997). Furthermore, this hypothesis is in general accord with the idea that a loss of PFC inhibitory control contributes importantly to behavioral sensitization. Experimental procedures that are able to probe the underlying structure of drug seeking to reveal whether it is under action-outcome or stimulus-response (habit) control are an important goal for future research.

We now have several clues about how repeated drug exposure may influence the activity of corticostriatal pathways. In naïve rats, excitatory synapses in DS and NAc exhibit both long-term depression (LTD) and LTP, although underlying mechanisms may differ between the two regions (Hyman and Malenka, 2001; Wolf, 2002). Striatal and NAc neurons are normally quiescent, and their activation requires synchronous activation of multiple excitatory inputs (O'Donnell and Grace, 1995). Thus, LTP or LTD in excitatory pathways impinging on these neurons would have profound effects on their output, because these processes influence synchronized activation. Several studies have found alterations in LTD and LTP in these pathways after chronic drug treatment (Wolf, 2002). Cocaine sensitization is accompanied by a reduction in the magnitude of AMPA receptor-mediated quantal events specifically at synapses in the NAc shell (but not core) that are activated by cortical afferents. Furthermore, the magnitude of LTD was reduced by repeated cocaine treatment, suggesting that long-lasting depression of excitatory synaptic transmission shares expression mechanisms with LTD (Thomas et al., 2001). Presynaptic mechanisms may also be involved, because repeated cocaine administration decreases glutamate immunolabeling in nerve terminals of the NAc shell (Meshul et al., 1998), an effect that appears more persistent when cocaine is selfadministered (Keys et al., 1998). These findings are in accord with others suggesting that the NAc is more quiescent after long-term withdrawal from repeated stimulant administration, perhaps re- flecting a combination of depressed excitatory transmission (White et al., 1995; Bibb et al., 2001; Thomas et al., 2001), decreased AMPA receptor subunit expression ( $\mathrm{Lu}$ and Wolf, 1999), and changes in voltage-dependent conductances (Zhang et al., 1998). Decreased excitability of the NAc could be specifically related to withdrawal phenomena, such as elevated reward thresholds (Markou and Koob, 1991) and anhedonia or dysphoria (Koob and Le Moal, 2001), that may also contribute to persistent cocaine seeking and relapse.

Psychostimulants therefore may influence LTP and LTD in corticostriatal and other pathways by acting at a systems level to alter neuronal activity in excitatory pathways. Repeated drug exposure produces early adaptations in glutamate receptor expression and DA and glutamate receptor responsiveness in the PFC (Li et al., 1999; Peterson et al., 2000), which might be responsible for triggering alterations in corticostriatal plasticity. Stimulants may also act directly on the mechanisms that enable synaptic plasticity, perhaps by influencing AMPA receptor phosphorylation or membrane trafficking (Bibb et al., 2001; Chao et al., 2002). Through such mechanisms, drugs may alter activity in neural systems underlying motivation and reward, leading to abnormal LTP or LTD, or directly modify the ability of neuronal activity to elicit appropriate forms of LTP and LTD. On the basis of studies in the hippocampus, a model has been proposed to explain the sequential changes that may lead from LTP and LTD to alterations in the biochemical composition of the postsynaptic membrane and ultimately to changes in the structure of dendritic spines (Lüscher et al., 2000). By tapping into LTP and LTD, psychostimulants could influence these fundamental processes, perhaps explaining the ability of repeated stimulant administration to produce changes in dendritic branching and spine density in the NAc and PFC, similar to those in other forms of experience-dependent plasticity (Robinson and Kolb, 1997, 1999; Robinson et al., 2001). Morphological changes are also implied by the demonstration of increased gap junction communication in the NAc and PFC after withdrawal from repeated amphetamine (Onn and Grace, 2000). Both types of morphological changes persist for at least 1 month and therefore are good candidates for mediating persistent alterations in the activity of systems that may underlie compulsive drug seeking.

\section{Summary}

There has been recent, substantial progress in understanding psychomotor stimulant, especially cocaine, addiction on two fronts: (1) characterization of the molecular basis of neuroadaptations induced by drugs of abuse and (2) identification of limbic cortical-ventral striatopallidal systems that underlie associative influences on cocaine-seeking behavior and relapse. A future challenge is to determine how particular neuroadaptations lead to plasticity in these systems, whether such changes are reversible, and how pharmacological treatments may be used to modify these processes and thereby reduce compulsive drug seeking and the propensity for relapse in human addicts.

\section{REFERENCES}

Altman J, Everitt BJ, Glautier S, Markou A, Nutt D, Oretti R, Phillips GD, Robbins TW (1996) The biological, social and clinical bases of drug addiction: commentary and debate. Psychopharmacology 125:285-345.

Arroyo M, Markou A, Robbins TW, Everitt BJ (1998) Acquisition, maintenance and reinstatement of intravenous cocaine selfadministration under a second-order schedule of reinforcement in rats: effects of conditioned cues and continuous access to cocaine. Psychopharmacology 140:331-344.

Badiani A, Oates MM, Day HEW, Watson SJ, Akil H, Robinson TE 
(1998) Amphetamine-induced behavior, dopamine release, and c-fos mRNA expression: modulation by environmental novelty. J Neurosci 18:10579-10593.

Badiani A, Oates MM, Day HEW, Watson SJ, Akil H, Robinson TE (1999) Environmental modulation of amphetamine-induced c-fos expression in D1 versus D2 striatal neurons. Behav Brain Res 103:203-209.

Baldwin AE, Holahan MR, Sadeghian K, Kelley AE (2000) N-methylD-aspartate receptor-dependent plasticity within a distributed corticostriatal network mediates appetitive instrumental learning. Behav Neurosci 114:84-98.

Bassareo V, Di Chiara G (1997) Differential influence of associative and nonassociative learning mechanisms on the responsiveness of prefrontal and accumbal dopamine transmission to food stimuli in rats fed ad libitum. J Neurosci 17:851-861.

Bell K, Kalivas PW (1996) Context-specific cross-sensitization between systemic cocaine and intra-accumbens AMPA infusion in the rat. Psychopharmacology 127:377-383.

Bell K, Duffy P, Kalivas PW (2000) Context-specific enhancement of glutamate transmission by cocaine. Neuropsychopharmacology 23:335-344.

Berke JD, Hyman SE (2000) Addiction, dopamine and the molecular mechanisms of memory. Neuron 25:515-532.

Bibb JA, Chen J, Taylor JR, Svenningsson P, Nishi A, Snyder GL, Yan Z, Sagawa ZK, Ouimet CC, Nairn AC, Nestler EJ, Greengard P (2001) Effects of chronic exposure to cocaine are regulated by the neuronal protein Cdk5. Nature 410:376-380.

Brown EE, Robertson GS, Fibiger HC (1992) Evidence for conditioned neuronal activation following exposure to a cocaine-paired environment: role of forebrain limbic structures. J Neurosci 12:4112-4121.

Burns LH, Robbins TW, Everitt BJ (1993) Differential effects of excitotoxic lesions of the basolateral amygdala, ventral subiculum and medial prefrontal cortex on responding with conditioned reinforcement and locomotor activity potentiated by intra-accumbens infusions of D-amphetamine. Behav Brain Res 55:167-183.

Cador M, Robbins TW, Everitt BJ (1989) Involvement of the amygdala in stimulus-reward associations: interaction with the ventral striatum. Neuroscience 30:77-86.

Carr DB, Sesack SR (2000) Projections form the rat prefrontal cortex to the ventral tegmental area: target specificity in the synaptic associations with mesoaccumbens and mesocortical neurons. J Neurosci 20:3864-3873.

Chao SZ, Lu W, Lee H-K, Huganir RL, Wolf ME (2002) D1 dopamine receptor stimulation increases GluR1 phosphorylation in postnatal nucleus accumbens cultures. J Neurochem, in press.

Childress AR, Ehrman R, Roohsenow DJ, Robbins SJ, O'Brien CP (1992) Classically conditioned factors in drug dependence. In: Substance abuse: a comprehensive text book (Lowinson W, Luiz P, Millman RB, Langard JG, eds), pp 56-69. Baltimore: Williams \& Wilkins.

Childress AR, McElgin W, Mozley PD, O’Brien CP (1999) Limbic activation during cue-induced craving for cocaine and for natural rewards. Biol Psychiat 45:170.

Ciccocioppo R, Sanna PP, Weiss F. (2001) Cocaine-predictive stimulus induces drug-seeking behavior and neural activation in limbic brain regions after multiple months of abstinence: reversal by D-1 antagonists. Proc Natl Acad Sci USA 98:1976-1981.

Corbit LH, Muir JL, Balleine BW (2001) The role of the nucleus accumbens in instrumental conditioning: evidence of a functional dissociation between accumbens core and shell. J Neurosci 21:3251-3260.

Cornish JL, Kalivas PW (2000) Glutamate transmission in the nucleus accumbens mediates relapse in cocaine addiction. J Neurosci 20:1-5.

Cornish JL, Duffy P, Kalivas PW (1999) A role for nucleus accumbens glutamate transmission in the relapse to cocaine-seeking behavior. Neuroscience 93:1359-1367.

Day HEW, Badiani A, Uslaner JM, Oates MM, Vittoz NM, Robinson TE, Watson Jr SJ, Akil H (2001) Environmental novelty differentially affects c-fos mRNA expression induced by amphetamine or cocaine in subregions of the bed nucleus of the stria terminalis and amygdala. J Neurosci 21:732-740.

Deroche V, Le Moal M, Piazza PV (1999) Cocaine self-administration increases the incentive motivational properties of the drug in rats. Eur J Neurosci 11:2731-2736.

De Vries TJ, Schoffelmeer ANM, Binnekade R, Mulder AH, Vanderschuren LJMJ (1998) Drug-induced reinstatement of heroin- and cocaine-seeking behaviour following long-term extinction is associated with expression of behavioural sensitization. Eur $\mathrm{J}$ Neurosci 10:3565-3571.

de Wit H, Stewart J (1981) Reinstatement of cocaine-reinforced responding in the rat. Psychopharmacology 75:134-143.

Di Chiara G, Imperato A (1988) Drugs abused by humans preferentially increase synaptic dopamine concentrations in the mesolimbic system of freely moving rats. Proc Natl Acad Sci USA 85:5274-5278.

Di Ciano P, Everitt BJ (2001) Dissociable effects of antagonism of NMDA and AMPA/KA receptors in the nucleus accumbens core and shell on cocaine-seeking behavior. Neuropsychopharmacology 25:341-360

Di Ciano P, Blaha CD, Phillips AG (1998) Conditioned changes in dopamine oxidation currents in the nucleus accumbens of rats by stimuli paired with self-administration or yoked-administration of D-amphetamine. Eur J Neurosci 10:1121-1127.

Di Ciano P, Underwood R, Hagan J, Everitt BJ (2001) Attenuation of drug-seeking by a selective D3 dopamine receptor antagonist. Soc Neurosci Abstr 27:647.9.

Everitt BJ, Robbins TW (2000) Second-order schedules of drug reinforcement in rats and monkeys: measurement of reinforcing efficacy and drug-seeking behaviour. Psychopharmacology 153:17-30.

Everitt BJ, Parkinson JA, Olmstead MC, Arroyo M, Robledo P, Robbins TW (1999) Associative processes in addiction and reward: the role of amygdala- ventral striatal subsystems. Ann NY Acad Sci 877:412-438.

Everitt BJ, Cardinal RN, Hall J, Parkinson JA, Robbins TW (2000) Differential involvement of amygdala subsystems in appetitive conditioning and drug addiction. In: The amygdala: a functional analysis (Aggleton JP, ed), pp 353-390. Oxford: Oxford UP.

Everitt BJ, Dickinson AD, Robbins TW (2001) The neuropsychological basis of addictive behaviour. Brain Res Rev 36:129-138.

Floresco SB, Todd CL, Grace AA (2001) Glutamatergic afferents from the hippocampus to the nucleus accumbens regulate activity of ventral tegmental area dopamine neurons. J Neurosci 21:4915-4922.

Forster GL, Blaha CD (2000) Laterodorsal tegmental stimulation elicits dopamine efflux in the rat nucleus accumbens by activation of acetylcholine and glutamate receptors in the ventral tegmental area. Eur J Neurosci 12:3596-3604.

Franklin TR, Druhan JP (2000a) Expression of Fos-related antigens in the nucleus accumbens and associated regions following exposure to a cocaine-paired environment. Eur J Neurosci 12:2097-2106.

Franklin TR, Druhan JP (2000b) Involvement of the nucleus accumbens and medial prefrontal cortex in the expression of conditioned hyperactivity to a cocaine-associated environment in rats. Neuropsychopharmacology 23:633-644.

George F, Aston-Jones G (2001) Potent regulation of midbrain dopamine neurons by the bed nucleus of the stria terminalis. J Neurosci 21:RC160(1-6).

Goldstein RZ, Volkow ND, Wang GJ, Fowler JS, Rajaram S (2001) Addiction changes orbitofrontal gyrus function: involvement in response inhibition. NeuroReport 12:2595-2599.

Grant S, London ED, Newlin DB, Villemagne VL, Xiang L, Contoreggi C, Phillips RL, Kimes AS, Margolin A (1996) Activation of memory circuits during cue-elicited cocaine craving. Proc Natl Acad Sci USA 93:12040-12045.

Grimm JW, See RE (2000) Dissociation of primary and secondary reward-relevant limbic nuclei in an animal model of relapse. Neuropsychopharmacology 22:473-479.

Grimm JW, Hope BT, Wise RA, Shaham Y (2001) Neuroadaptation: incubation of cocaine craving after withdrawal. Nature 412:141-142.

Haber SN, Fudge JL, McFarland NR (2000) Striatonigral pathways in primates form an ascending spiral from the shell to the dorsolateral striatum. J Neurosci 20:2369-2382.

Hall J, Parkinson JA, Connor TM, Dickinson A, Everitt BJ (2001) Involvement of amygdalo-striatal sub-systems in pavlovian to instrumental transfer. Eur J Neurosci 13:1984-1992.

Hitchcott PK, Phillips GD (1998) Double dissociation of the behavioural effects of $\mathrm{R}(+)$ 7-OH-DPAT infusions in the central and basolateral amygdala nuclei on pavlovian and instrumental conditioned appetitive behaviours. Psychopharmacology 140:458-469.

Holland PC, Gallagher M (1999) Amygdala circuitry in attentional and representational processes. Trends Cogn Sci 3:65-73.

Horger BA, Shelton K, Schenk S (1990) Preexposure sensitises rats to the rewarding effects of cocaine. Pharmacol Biochem Behav 37: $707-711$.

Hotsenpiller G, Horak BT, Wolf ME (2002) Dissociation of conditioned locomotion and Fos induction in response to stimuli formerly paired with cocaine. Behav Neurosci, in press.

Hotsenpiller G, Giorgetti M, Wolf ME (2001) Alterations in behaviour and glutamate transmission following presentation of stimuli previously associated with cocaine exposure. Eur J Neurosci 14:1843-1855.

Hyman SE, Malenka RC (2001) Addiction and the brain: the neurobiology of compulsion and its persistence. Nat Rev Neurosci 2:695-703.

Ito R, Dalley JW, Howes SR, Robbins TW, Everitt BJ (2000) Dissociation in conditioned dopamine release in the nucleus accumbens core and shell in response to cocaine cues and during cocaine-seeking behavior in rats. J Neurosci 20:7489-7495.

Ito R, Robbins TW, Everitt BJ (2001) Dissociation in the effects of lesions of the nucleus accumbems core and shell on the acquisition of a second-order schedule of cocaine reinforcement. Soc Neurosci Abstr 27:443.9.

Jentsch JD, Taylor JR (1999) Impulsivity resulting from frontostriatal dysfunction in drug abuse: implications for the control of behavior by reward-related stimuli. Psychopharmacology 146:373-390.

Jentsch JD, Olausson P, De La Garza R, Taylor JR (2002) Impairments 
of reversal learning and response perseveration after repeated, intermittent cocaine administrations to monkeys. Neuropsychopharmacology 26:183-190.

Kaddis FG, Uretsky NJ, Wallace LJ (1995) DNQX in the nucleus accumbens inhibits cocaine-induced conditioned place preference. Brain Res 697:76-82.

Kalivas PW, Alesdatter JE (1993) Involvement of $N$-methyl-D-aspartate receptor stimulation in the ventral tegmental area and amygdala in behavioral sensitization to cocaine. J Pharmacol Exp Ther 267:486495.

Kantak KM, Black Y, Valencia E, Green-Jordan K, Eichenbaum HB (2002) Dissociable effects of lidocaine inactivation of the rostral and caudal basolateral amygdala on the maintenance and reinstatement of cocaine-seeking behavior in rats. J Neurosci 22:1126-1136.

Karler R, Calder LD, Thai DK, Bedingfield JB (1998) The role of dopamine in the mouse frontal cortex: a new hypothesis of behavioural sensitization to amphetamine and cocaine. Pharmacol Biochem Behav 61:435-443.

Kelley AE, Smith-Roe SL, Holahan MR (1997) Response-reinforcement learning is dependent on $N$-methyl-D-aspartate receptor activation in the nucleus accumbens core. Proc Natl Acad Sci USA 94:12174-12179.

Keys AS, Mark GP, Emre N, Meshul CK (1998) Reduced glutamate immunolabeling in the nucleus accumbens following extended withdrawal from self-administered cocaine. Synapse 30:393-401.

Khan MA, Shoaib M (1996) Neuroanatomical localization of the effects of (+)-HA966 on locomotor activity after cocaine injections into the nucleus accumbens of rats. Brain Res 719:198-202.

Koob GF (1992) Dopamine, addiction and reward. Semin Neurosci 4:139-148.

Koob GF, Le Moal M (2001) Drug addiction, dysregulation of reward, and allostasis. Neuropsychopharmacology 24:97-129.

Kruzich PJ, See RE (2001) Differential contributions of the basolateral and central amygdala in the acquisition and expression of conditioned relapse to cocaine-seeking behavior. J Neurosci 21:U16-U20.

Kruzich PJ, Congleton KM, See RE (2001) Conditioned reinstatement of drug-seeking behavior with a discrete compound stimulus classically conditioned with intravenous cocaine. Behav Neurosci 115:1086-1092.

Layer RT, Uretsky NJ, Wallace LJ (1993) Effects of the AMPA/kainite receptor antagonist DNQX in the nucleus accumbens on drug-induced conditioned place preference. Brain Res 617:267-273.

Leshner AI (1997) Addiction is a brain disease, and it matters. Science 278:45-47.

Letchworth SR, Nader MA, Smith HR, Friedman DP, Porrino LJ (2001) Progression of changes in dopamine transporter binding site density as a result of cocaine self-administration in rhesus monkeys. J Neurosci 21:2799-2807

Lewis B, O'Donnell P (2000) Ventral tegmental area afferents to the prefrontal cortex maintain membrane potential "up" states in pyramidal neurons via D1 dopamine receptors. Cereb Cortex 10:1168-1175.

Li Y, Hu X-T, Berney TG, Vartanian AJ, Stine CD, Wolf ME, White FJ (1999) Both glutamate receptor antagonists and prefrontal cortex lesions prevent induction of cocaine sensitization and associated neuroadaptations. Synapse 34:169-180.

Lorrain DS, Arnold GM, Vezina P (2000) Previous exposure to amphetamine increases incentive to obtain the drug: long-lasting effects revealed by the progressive ratio schedule. Behav Brain Res 107:9-19.

Lu W, Wolf ME (1999) Repeated amphetamine administration alters immunoreactivity for AMPA receptor subunits in rat nucleus accumbens and medial prefrontal cortex. Synapse 32:119-131.

Lüscher C, Nicoll RA, Malenka RC, Muller D (2000) Synaptic plasticity and dynamic modulation of the postsynaptic membrane. Nat Neurosci 3:545-550.

Maas LC, Lukas SE, Kaufman MJ, Weiss RD, Daniels SL, Rogers VW, Kukes TJ, Renshaw PF (1998) Functional magnetic resonance imaging of human brain activation during cue-induced cocaine craving. Am J Psychiat 155:124-126.

Markou A, Koob GF (1991) Postcocaine anhedonia: an animal model of cocaine withdrawal. Neuropsychopharmacology 4:17-26.

McDonald RJ, White NM (1993) A triple dissociation of memory systems: hippocampus, amygdala and dorsal striatum. Behav Neurosci 107:3-22.

McFarland K, Kalivas PW (2001) The circuitry mediating cocaineinduced reinstatement of drug-seeking behavior. J Neurosci 21:86558663.

Mead AN, Vasilaki A, Spyraki C, Duka T, Stephens DN (1999) AMPAreceptor involvement in c-fos expression in the medial prefrontal cortex and amygdala dissociates neural substrates of conditioned activity and conditioned reward. Eur J Neurosci 11:4089-4098.

Meil WM, See RE (1996) Conditioned cue recovery of responding following prolonged withdrawal from self-administered cocaine in rats: an animal model of relapse. Behav Pharmacol 7:754-763.

Meil WM, See RE (1997) Lesions of the basolateral amygdala abolish the ability of drug associated cues to reinstate responding during withdrawal from self-administered cocaine. Behav Brain Res 1997:139-148.
Mendrek A, Blaha CD, Phillips AG (1998) Pre-exposure of rats to amphetamine sensitises self-administration of this drug under a progressive ratio schedule. Psychopharmacology 135:416-422.

Meshul CK, Noguchi K, Emre N, Ellison G (1998) Cocaine-induced changes in glutamate and GABA immunolabeling within rat habenula and nucleus accumbens. Synapse 30:211-220.

Mishkin M, Malamut B, Bachevalier J (1984) Memories and habits: two neural systems. In: Neurobiology of human learning and memory (McGaugh JL, Weinberger NM, eds), pp 65-87. New York: Guildford.

Neisewander JL, Baker DA, Fuchs RA, Tran-Nguyen TL, Palmer A, Marshall JF (2000) Fos protein expression and cocaine-seeking behavior in rats after exposure to a cocaine self-administration environment. J Neurosci 20:798-805.

Nestler EJ (2001) Molecular basis of long-term plasticity underlying addiction. Nat Rev Neurosci 2:119-128.

O'Brien CP, McLellan AT (1996) Myths about the treatment of addiction. Lancet 347:237-240.

O’Brien CP, Childress AR, McLellan T, Ehrman R (1990) Integrating systematic cue exposure with standard treatment in recovering drug dependent patients. Addict Behav 15:355-365.

O’Brien CP, Childress AR, McLellan AT, Ehrman R (1992) A learning model of addiction. Res Pub Assoc Res Nerv Ment Dis 70:157-177.

O’Donnell P, Grace AA (1995) Synaptic interactions among excitatory afferents to nucleus accumbens: hippocampal gating of prefrontal cortical input. J Neurosci 15:3622-3639.

Onn S-P, Grace AA (2000) Amphetamine withdrawal alters bistable states and cellular coupling in rat prefrontal cortex and nucleus accumbens neurons recorded in vivo. J Neurosci 20:2332-2345.

Packard MG, McGaugh JL (1996) Inactivation of hippocampus or caudate nucleus with lidocaine differentially affects expression of place and response learning. Neurobiol Learn Mem 65:65-72.

Packard MG, White NM (1989) Memory facilitation produced by dopamine agonists: role of receptor subtype and mnemonic requirements. Pharmacol Biochem Behav 33:511-518.

Packard MG, White NM (1991) Dissociation of hippocampus and caudate nucleus memory systems by posttraining intracerebral injection of dopamine agonists. Behav Neurosci 105:295-306.

Parkinson JA, Cardinal RN, Everitt BJ (2000a) Limbic cortical-ventral striatal systems underlying appetitive conditioning. In: Cognition, emotion and autonomic responses: the integrative role of the prefrontal cortex and limbic structures (Uylings HBM, van Eden CG, de Bruin JPC, Feenstra MGP, Pennartz CMA, eds), pp 263-286. Amsterdam: Elsevier.

Parkinson JA, Willoughby PJ, Robbins TW, Everitt BJ (2000b) Disconnection of the anterior cingulate cortex and nucleus accumbens core impairs pavlovian approach behavior: further evidence for limbic cortico-ventral striatopallidal systems. Behav Neurosci 114:42-63.

Peterson JD, Wolf ME, White FJ (2000) Altered responsiveness of medial prefrontal cortex neurons to glutamate and dopamine after withdrawal from repeated amphetamine treatment. Synapse 36:342-344.

Pierce RC, Reeder DC, Hicks J, Morgan ZR, Kalivas PW (1998) Ibotenic acid lesions of the dorsal prefrontal cortex disrupt the expression of behavioral sensitization to cocaine. Neuroscience 82:1103-1114.

Pilla M, Perachon S, Sautel F, Garrido F, Mann A, Wermuth CG, Schwartz JC, Everitt BJ, Sokoloff P (1999) Selective inhibition of cocaine-seeking behaviour by a partial dopamine D-3 receptor agonist. Nature 400:371-375.

Prasad BM, Hochstatter T, Sorg BA (1999) Expression of cocaine sensitization: regulation by the medial prefrontal cortex. Neuroscience 88:765-774.

Robbins SJ, Ehrman RN, Childress AR, O'Brien CP (1992) Using cue reactivity to screen medications for cocaine abuse: a test of amantadine hydrochloride. Addict Behav 17:491-499.

Robbins TW, Everitt BJ (1999) Drug addiction: bad habits add up. Nature 398:567-570

Robbins TW, Giardini V, Jones GH, Reading P, Sahakian BJ. (1990) Effects of dopamine depletion from the caudate-putamen and nucleus accumbens septi on the acquisition and performance of a conditional discrimination task. Behav Brain Res 38:243-261.

Robinson TE, Berridge KC (1993) The neural basis of drug craving: an incentive-sensitization theory of addiction. Brain Res Rev 18:247-291.

Robinson TE, Kolb B (1997) Persistent structural modifications in nucleus accumbens and prefrontal cortex neurons produced by previous experience with amphetamine. J Neurosci 17:8491-8497.

Robinson TE, Kolb B (1999) Alterations in the morphology of dendrites and dendritic spines in the nucleus accumbens and prefrontal cortex following repeated treatment with amphetamine or cocaine. Eur J Neurosci 11:1598-1604.

Robinson TE, Browman KE, Crombag HS, Badiani A (1998) Modulation of the induction or expression of psychostimulant sensitization by the circumstances surrounding drug administration. Neurosci Biobehav Rev 22:347-354.

Robinson TE, Gorny G, Mitton E, Kolb B (2001) Cocaine self- 
administration alters the morphology of dendrites and dendritic spines in the nucleus accumbens and neocortex. Synapse 39:257-266.

Rogers RD, Everitt BJ, Baldacchino A, Blackshaw AJ, Swainson R, Wynne K, Baker NB, Hunter J, Carthy T, Booker E, London M, Deakin JFW, Sahakian BJ, Robbins TW (1999) Dissociable deficits in the decision-making cognition of chronic amphetamine abusers, opiate abusers, patients with focal damage to prefrontal cortex, and tryptophan-depleted normal volunteers: evidence for monoaminergic mechanisms. Neuropsychopharmacology 20:322-339.

Rosenkranz JA, Grace AA (2001) Dopamine attenuates prefrontal cortical suppression of sensory inputs to the basolateral amygdala of rats. J Neurosci 21:4090-4103.

Schultz W, Dickinson A (2000) Neuronal coding of prediction errors. Annu Rev Neurosci 23:473-500.

Schultz W, Dayan P, Montague PR (1997) A neural substrate of prediction and reward. Science 275:1593-1599.

See RE, Kruzich PJ, Grimm JW (2001) Dopamine, but not glutamate, receptor blockade in the basolateral amygdala attenuates conditioned reward in a rat model of relapse to cocaine-seeking behavior. Psychopharmacology 154:301-310.

Selden NRW, Everitt BJ, Jarrard LE, Robbins TW (1991) Complementary roles for the amygdala and hippocampus in aversive conditioning to explicit and contextual cues. Neuroscience 42:335-350.

Self DW, Nestler EJ (1998) Relapse to drug-seeking: neural and molecular mechanisms. Drug Alchol Depend 51:49-60.

Self DW, Barnhardt WJ, Lehman DA, Nestler EJ (1996) Opposite modulation of cocaine-seeking behaviour by D1- and D2-like dopamine receptor agonists. Science 271:1586-1589.

Shaham Y, Rodaros D, Stewart J (1994) Reinstatement of heroinreinforced behavior following long-term extinction: implications for the treatment of relapse to drug-taking. Behav Pharmacol 5:360-364.

Shallice T (1996) The domain of supervisory processes and temporal organization of behaviour. Philos Trans R Soc Lond B Biol Sci 351:1405-1412.

Smith-Roe SL, Kelley AE (2000) Coincident activation of NMDA and dopamine D-1 receptors within the nucleus accumbens core is required for appetitive instrumental learning. J Neurosci 20:7737-7742.

Taylor JR, Horger BA (1999) Enhanced responding for conditioned reward produced by intra-accumbens amphetamine is potentiated after cocaine sensitization. Psychopharmacology 142:31-40.

Taylor JR, Jentsch JD (2001) Repeated intermittent administration of psychomotor stimulant drugs alters the acquisition of pavlovian approach behavior in rats: differential effects of cocaine, D-amphetamine and 3,4-methylenedioxymethamphetamine ("Ecstasy"). Biol Psychiat 50:137-143.

Taylor JR, Robbins TW (1986) 6-Hydroxydopamine lesions of the nucleus accumbens, but not of the caudate nucleus, attenuate enhanced responding with reward-related stimuli produced by intra-accumbens D-amphetamine. Psychopharmacology 90:390-397.

Thomas KL, Everitt BJ (2001) Limbic cortical-ventral striatal activation during retrieval of a discrete cocaine-associated stimulus: a cellular imaging study with G-protein kinase $\mathrm{C}$ expression. J Neurosci $21: 2526-2535$.

Thomas MJ, Beurrier C, Bonci A, Malenka RC (2001) Long-term depression in the nucleus accumbens: a neural correlate of behavioral sensitization to cocaine. Nat Neurosci 4:1217-1223.

Ungless MA, Whisler JL, Malenka RC, Bonci A (2001) Single cocaine exposure in vivo induces long-term potentiation in dopamine neurons. Nature 411:583-587.

Uslaner J, Badiani A, Norton CS, Day HEW, Watson SJ, Akil H, Robinson TE (2001) Amphetamine and cocaine induce different patterns of c-fos mRNA expression in the striatum and subthalamic nu- cleus depending on environmental context. Eur J Neurosci 13:1977-1983.

Volkow ND, Fowler JS (2000) Addiction, a disease of compulsion and drive: involvement of the orbitofrontal cortex. Cereb Cortex 10:318-325.

Vorel SR, Liu X, Hayes RJ, Spector JA, Gardner EL (2001) Relapse to cocaine-seeking after hippocampal theta burst stimulation. Science 292:1175-1178.

Wang GJ, Volkow ND, Fowler JS, Cervany P, Hitzemann RJ, Pappas NR, Wong CT, Felder C (1999) Regional brain metabolic activation during craving elicited by recall of previous drug experiences. Life Sci 64:775-784.

Weiss F, Maldonado-Vlaar CS, Parsons LH, Kerr TM, Smith DL, BenShahar O (2000) Control of cocaine-seeking behavior by drugassociated stimuli in rats: effects on recovery of extinguished operantresponding and extracellular dopamine levels in amygdala and nucleus accumbens. Proc Natl Acad Sci USA 97:4321-4326.

Weiss F, Martin-Fardon R, Ciccocioppo R, Kerr TM, Smith DL, BenShahar O (2001) Enduring resistance to extinction of cocaine-seeking behavior induced by drug-related cues. Neuropsychopharmacology 25:361-372

Weissenborn R, Robbins TW, Everitt BJ (1997) Effects of medial prefrontal or anterior cingulate cortex lesions on responding for cocaine under fixed-ratio and second-order schedules of reinforcement in rats. Psychopharmacology 134:242-257.

White FJ, Hu X-T, Zhang X-F, Wolf ME (1995) Repeated administration of cocaine or amphetamine alters neuronal responses to glutamate in the mesoaccumbens dopamine system. J Pharmacol Exp Ther 273:445-454.

Whitelaw RB, Markou A, Robbins TW, Everitt BJ (1996) Excitotoxic lesions of the basolateral amygdala impair the acquisition of cocaineseeking behaviour under a second-order schedule of reinforcement Psychopharmacology 127:213-224.

Wise RA (1981) Brain dopamine and reward. In: Theory in psychopharmacology (Cooper SJ, ed), pp 102-122. London: Academic.

Wolf ME (1998) The role of excitatory amino acids in behavioral sensitization to psychomotor stimulants. Prog Neurobiol 54:679-720.

Wolf ME (2001) The neuroplasticity of addiction. In Toward a theory of neuroplasticity (Shaw C, McEachern J, eds), pp 359-372. Philadelphia: Taylor \& Francis Group.

Wolf ME (2002) Addiction and glutamate-dependent plasticity. In: Glutamate and addiction (Herman BH, Frankenheim J, Litten R, Sheridan PH, Weight FF, Zukin SR, eds). Totowa, NJ: Humana, in press.

Wolf ME, Dahlin SL, Hu X-T, Xue C-J, White K (1995) Effects of lesions of prefrontal cortex, amygdala, or fornix on behavioral sensitization to amphetamine: comparison with $N$-methyl-D-aspartate antagonists. Neuroscience 69:417-439.

Wolterink G, Phillips G, Cador M, Donselaar-Wolterink I, Robbins TW, Everitt BJ (1993) Relative roles of ventral striatal D1 and D2 dopamine receptors in responding with conditioned reinforcement. Psychopharmacology 110:355-364

Wyvell CL, Berridge KC (2000) Intra-accumbens amphetamine increases the conditioned incentive salience of sucrose reward: enhancement of reward "wanting" without enhanced "liking" or response reinforcement. J Neurosci 20:8122-8130.

Wyvell CL, Berridge KC (2001) Incentive sensitization by previous amphetamine exposure: increased cue-triggered "wanting" for sucrose. J Neurosci 21:7831-7840.

Zhang X-F, Hu X-T, White FJ (1998) Whole-cell plasticity in cocaine withdrawal: reduced sodium currents in nucleus accumbens neurons J Neurosci 18:488-498. 